\title{
GERMINAÇÃO, VIGOR DE SEMENTES E CRESCIMENTO DE PLÂNTULAS DE MILHO SOB CONDIÇÕES DE DÉFICIT HÍDRICO
}

\section{GERMINATION, SEED VIGOR AND SEEDLING GROWTH OF CORN ON HIDRIC STRESS CONDITIONS}

\author{
Claudinei KAPPES ${ }^{1}$ \\ João Antônio da Costa ANDRADE ${ }^{2}$ \\ Kuniko Iwamoto HAGA ${ }^{3}$ \\ João Paulo FERREIRA ${ }^{4}$ \\ Marcelo Valentini ARF
}

\section{RESUMO}

A disponibilidade hídrica e o movimento de água para as sementes são importantes para a germinação e emergência das plântulas, sendo estes fatores influenciados pelo potencial hídrico do solo. Assim, este trabalho teve por objetivo avaliar a germinação, o vigor de sementes e o crescimento de plântulas de híbridos de milho (XB 6010, XB 6012, XB 9003 e AG 9010) submetidas a condições de déficit hídrico. As sementes foram semeadas em rolos de papel toalha umedecidos com soluções de manitol, utilizando-se cinco níveis de potencial osmótico: 0,0 (testemunha); -0,3; -0,6; -0,9 e -1,2 MPa. Foram avaliadas a primeira contagem, contagem final e velocidade de germinação, comprimento da raiz primária e da parte aérea, relação parte aérea/raiz e biomassa fresca e seca de plântula. As médias dos híbridos foram comparadas pelo teste de Tukey $(P<0,05)$ e as médias dos níveis de potencial osmótico pela análise de regressão. Exceto para biomassa seca de plântula, houve interação entre os fatores para todos os testes, demonstrando que os híbridos tiveram comportamento distinto entre si em relação ao déficit hídrico induzido por manitol. O déficit hídrico provoca redução no desempenho de sementes de híbridos de milho, sendo que estes apresentam comportamento diferenciado entre si quanto à tolerância em tal condição. Há redução da germinação, do vigor de sementes e do crescimento de plântulas de milho à medida que o potencial osmótico torna-se mais negativo.

Palavras-chave: Zea mays (L.); restrição hídrica; manitol; potencial osmótico.

\section{ABSTRACT}

The water availability and movement of water to the seeds are important for germination and seedling emergence, and these factors are influenced by soil water potential. Thus, this study was evaluated the germination, seed vigor and seedling growth of corn (XB 6010, XB 6012, XB 9003 and AG 9010) submited to hidric stress conditions. The seeds were sowing in paper towels moistened with mannitol solutions, using five levels of osmotic potential: 0.0 (control), $-0.3,-0.6,-0.9$ and -1.2 $\mathrm{MPa}$. We evaluated the first count, and rate of germination, primary root length and shoot for shoot/root and fresh weight of seedlings. The average of hybrids were compared by Tukey test $(P<0.05)$ and the mean levels of osmotic potential by regression analysis. Except for biomass of the seedling, there was an interaction between the factors for all tests, showing that the hybrids had a distinct behavior between them in relation to water stress induced by mannitol. Drought causes a reduction in the performance of hybrid seed corn, and they have behaved differently from each other as the tolerance in this condition. A reduction of germination, seed vigor and growth of maize seedlings as the osmotic potential of water becomes more negative.

Key-words: Zea mays (L.); water restriction; mannitol; osmotic potential.

\footnotetext{
${ }^{1}$ Engenheiro Agrônomo, Bolsista CAPES, Mestrando do Programa de Pós-Graduação em Agronomia da Universidade Estadual Paulista "Júlio de Mesquita Filho" (UNESP), Departamento de Fitotecnia, Tecnologia de Alimentos e Sócio Economia, Avenida Brasil, 56, Centro, CEP 15385000, Ilha Solteira, São Paulo, Brasil. E-mail: code.agro@hotmail.com. Autor para correspondência.

2 Engenheiro Agrônomo, Doutor em Agronomia, Professor Assistente do Departamento de Biologia e Zootecnia da Universidade Estadual Paulista "Júlio de Mesquita Filho" (UNESP), Ilha Solteira, São Paulo, Brasil. E-mail: jandrade@bio.feis.unesp.br

${ }^{3}$ Bióloga, Doutora em Biologia Vegetal, Professora Assistente do Departamento de Biologia e Zootecnia da Universidade Estadual Paulista "Júlio de Mesquita Filho" (UNESP), Ilha Solteira, São Paulo, Brasil. E-mail: kuniko@bio.feis.unesp.br

${ }^{4}$ Engenheiro Agrônomo, Ilha Solteira, São Paulo, Brasil. E-mail: ferreirajpferreira@gmail.com

${ }^{5}$ Engenheiro Agrônomo, Bolsista Fundação de Amparo à Pesquisa do Estado de São Paulo (FAPESP), Mestrando do Programa de PósGraduação em Agronomia da Universidade Estadual Paulista "Júlio de Mesquita Filho" (UNESP), Ilha Solteira, São Paulo, Brasil. E-mail: marceloarf@hotmail.com.
} 
KAPPES, C. et al. Germinação, vigor de sementes e crescimento...

\section{INTRODUÇÃO}

A base da alta produção por área de qualquer cultura está relacionada ao estabelecimento das plantas no campo, que por sua vez, depende do manejo racional e da qualidade das sementes utilizadas (Machado et al., 2001). Assim como as demais culturas, o milho [(Zea mays (L.)] também está sujeito às condições adversas no campo, como problemas relacionados à disponibilidade hídrica na época de semeadura, afetando a germinação das sementes, a qual é caracterizada como um processo irreversível e um dos estádios mais críticos do ciclo de vida da planta (Almansouri et al., 2001). Khajeh-Hosseini et al. (2003) afirmaram que, dos diversos fatores ambientais capazes de influenciar a germinação, a disponibilidade de água é um dos mais importantes, pois se constitui a matriz onde ocorre a maioria dos processos bioquímicos e fisiológicos. Os efeitos da disponibilidade hídrica se prolongam após a emergência do eixo embrionário, com reflexos sobre o desenvolvimento das plântulas.

A primeira etapa da germinação se processa com a absorção de água pela semente, mediante embebição (Taiz \& Zeiger, 2004). Da absorção de água resulta a reidratação dos tecidos, com a conseqüente intensificação da respiração e de todas as demais atividades metabólicas que culminam com o fornecimento de energia e de nutrientes necessários para a retomada do crescimento do eixo embrionário (Carvalho \& Nakagawa, 2000). O movimento e a disponibilidade de água para as sementes são fundamentais para a germinação, crescimento inicial do sistema radicular e emergência das plântulas, sendo estes fatores influenciados pelas características do complexo coloidal do substrato, ou seja, o potencial osmótico do solo (Bewley \& Black, 1994).

Potenciais osmóticos muitos negativos, especialmente no início da embebição, influenciam a absorção de água, atrasando e diminuindo a germinação (Botelho \& Perez, 2001). O estresse hídrico normalmente diminui a porcentagem e a velocidade de germinação, predispondo a semente e a plântula a uma menor resistência a condições ambientais adversas, bem como ao ataque de patógenos. Contudo, existe variação entre as espécies (Bewley \& Black, 1994), sendo que para cada espécie existe um valor de potencial osmótico no solo, abaixo do qual a germinação não ocorre. Potenciais osmóticos do substrato de $-0,4$ e $-0,6$ $\mathrm{MPa}$ causaram sensível redução na porcentagem de germinação, nas plântulas normais obtidas na primeira contagem do teste de germinação, na velocidade de germinação, no comprimento do hipocótilo e da radícula e na massa seca das plântulas de feijão (Braga et al., 1999). Silva et al. (2005) verificaram que as sementes de Cnidosculus juercifolius apresentaram bom desempenho germinativo até o potencial de -0,3 MPa e que a porcentagem de germinação foi afetada a partir de $0,5 \mathrm{MPa}$, enquanto sua velocidade foi reduzida a partir de $-0,3 \mathrm{MPa}$.
Um dos métodos mais difundidos para determinação da tolerância das plantas aos estresses abióticos é a observação da capacidade germinativa das sementes nestas condições. Alguns trabalhos de germinação têm sido conduzidos em laboratório utilizando-se soluções preparadas com reagentes quimicamente inertes e não tóxicos às sementes e plântulas (MartinelliSeneme et al., 2000), como o uso de soluções aquosas de manitol, a fim de simular condições padronizadas de estresse hídrico para seleção de espécies mais tolerantes, conforme observaram Tonin et al. (2000), em genótipos de milho. Nesse contexto, a utilização de sementes com elevado vigor é essencial para a germinação mais rápida e uniforme das plântulas sob ampla diversidade de condições ambientais, propiciando a obtenção de adequado estande de plantas no campo.

Considerando a importância da água para a germinação das sementes, propôs-se o presente estudo com o objetivo de avaliar a germinação, o vigor de sementes e o crescimento de plântulas de quatro híbridos de milho em condições de déficit hídrico induzido por soluções de manitol.

\section{MATERIAL E MÉTODOS}

O ensaio foi conduzido durante o período compreendido entre março e abril de 2009 no Laboratório de Fisiologia Vegetal do Departamento de Biologia e Zootecnia da Universidade Estadual Paulista "Júlio de Mesquita Filho" (UNESP), Ilha Solteira, São Paulo.

Foram estabelecidos vinte tratamentos, resultantes da combinação entre híbridos de milho e níveis de potencial osmótico. O delineamento experimental utilizado foi o inteiramente casualizado (D.I.C.), arranjados no esquema fatorial $4 \times 5$ (híbridos de milho $\mathrm{x}$ níveis de potencial osmótico, respectivamente), com quatro repetições. Foram utilizadas sementes comerciais de quatro híbridos simples de milho provenientes da safra 2008/08: XB 6010, XB 6012 e XB 9003 da empresa Sementes Semeali $^{\circledR}$ e AG 9010 da Sementes Agroceres ${ }^{\circledR}$ (Tabela 1). Os níveis de potencial osmótico foram 0,$0 ;-0,3 ;-0,6 ;-0,9$ e $-1,2 \mathrm{MPa}$. O nível zero de potencial osmótico foi utilizado como testemunha, utilizando-se apenas água desmineralizada para hidratar o substrato. Para obtenção do potencial osmótico desejado, foram utilizadas concentrações de manitol (Tabela 2), calculadas pela fórmula de Van't Hoff, citado por Salisbury \& Ross (1992), conforme a equação Yos $=-R T C$, onde Yos: potencial osmótico (MPa); R: constante geral dos gases perfeitos $\left(0,082 \mathrm{MPa} \mathrm{dm} \mathrm{mol}^{-1} \mathrm{~K}^{-1}\right) ; T$ : temperatura $\left({ }^{\circ} \mathrm{K}\right)$; e $\mathrm{C}$ : concentração $\left(\mathrm{mol} \mathrm{dm}^{-3}\right)$.

Os testes de germinação, vigor de sementes e o crescimento de plântulas, em condições de déficit hídrico simuladas com soluções de manitol, foram realizados em substrato de papel-toalha (Germitest) hidratado com volume de solução equivalente a 2,5 vezes a sua massa. Para cada rolo confeccionado, foram utilizadas três folhas de papel-toalha. O vigor das sementes foi avaliado 
KAPPES, C. et al. Germinação, vigor de sementes e crescimento...

TABELA 1 - Massa média de cem sementes (M.C.S.) e classificação das sementes dos híbridos utilizados no estudo. UNESP, Ilha Solteira, São Paulo, Brasil (2009).

\begin{tabular}{lcccc}
\hline Característica & XB 6010 & XB 6012 & XB 9003 & AG 9010 \\
\hline M.C.S. $(\mathrm{g})^{1}$ & 36,3 & 30,8 & 37,0 & 32,8 \\
Categoria & S1 & S1 & S1 & S1 \\
Lote & S.I. & SBI 421-32 & SBI 422-06 & IJH01259 \\
Peneira & S.I. & C2M & C2M & C2G \\
\hline
\end{tabular}

Com base em $130 \mathrm{~g} \mathrm{~kg}^{-1}$ de teor de água. S1 - Sementes da classe não certificada; S.I. - Sem informação. C2M - Peneira chata 22 média; C2G - Peneira chata 22 grande.

TABELA 2 - Quantidade de manitol utilizada para o preparo das soluções nos diferentes níveis de potencial osmótico. UNESP, Ilha Solteira, São Paulo, Brasil (2009).

\begin{tabular}{cc}
\hline Níveis $\Psi_{\text {os }}(\mathrm{MPa})$ & Manitol \\
\cline { 2 - 2 } & $\left(\mathrm{g} \mathrm{dm}^{-3}\right.$ de água desmineralizada $)$ \\
$-0,0$ & 0,0 \\
$-0,6$ & 22,079 \\
$-0,9$ & 44,158 \\
$-1,2$ & 66,237 \\
\hline
\end{tabular}

através do teste da primeira contagem e da velocidade de germinação. O teste de germinação foi conduzido com quatro sub-amostras de 50 sementes para cada tratamento, de acordo com os critérios estabelecidos nas Regras para Análise de Sementes (BRASIL, 1992). Os rolos confeccionados, com três folhas de papel-toalha, foram acondicionados em câmara germinadora do tipo B.O.D. (modelo MA 415), regulado para manter temperatura constante de $25 \pm 2{ }^{\circ} \mathrm{C}$. A avaliação da primeira contagem de germinação foi realizada no quarto dia após a instalação do teste. A contagem final de germinação (segunda contagem), obtida pela somatória com a primeira contagem de germinação, foi realizada no sétimo dia após a instalação do teste. Os dados foram convertidos para porcentagem de plântulas normais (BRASIL, 1992). Assim, a primeira contagem e velocidade de germinação foi um indicativo do vigor das sementes e a contagem final, da viabilidade.

A velocidade de germinação foi calculada pela fórmula de Edmond \& Drapala (1958): V.G.= $\left[\left(D_{1} \times P_{1}\right)+\left(D_{2} \times P_{2}\right)\right] /\left(P_{1}+P_{2}\right)$, onde: V.G. é a velocidade de germinação expressa em número de dias médios para a germinação; $D_{1}$ e $D_{2}$ correspondem aos números de dias da semeadura à primeira e segunda contagem, respectivamente; $P_{1}$ e $P_{2}$ correspondem aos números de plântulas normais na primeira e segunda contagem de germinação, respectivamente.

A avaliação do crescimento das plântulas foi realizada apenas nas plântulas normais, eliminando-se as anormais e as sementes mortas, mensurando o comprimento da raiz primária, comprimento da parte aérea e biomassa fresca e seca de plântula. O substrato foi preparado da mesma maneira descrita para 0 teste de germinação, sendo utilizadas quatro sub-amostras de 25 sementes para cada tratamento. Os rolos confeccionados permaneceram por sete dias no germinador B.O.D. a $25 \pm 2{ }^{\circ} \mathrm{C}$. Entretanto, para a determinação do comprimento médio da raiz primária e da parte aérea foram consideradas aleatoriamente quatro sub-amostras com 10 plântulas normais por tratamento. A avaliação foi realizada no sétimo dia após a instalação do teste, com auxilio de régua milimetrada e os resultados médios foram expressos em $\mathrm{cm}$ plântula ${ }^{-1}$. Determinou-se ainda a relação parte aérea/raiz de plântulas, pela simples divisão do comprimento médio da parte aérea pelo comprimento médio da raiz primária.

A determinação da biomassa fresca de plântula foi realizada após a avaliação do comprimento da raiz e da parte aérea. Nesta avaliação, foram consideradas todas as plântulas normais originadas nos respectivos tratamentos, as quais foram pesadas em balança de precisão $(0,01$ g). A massa total obtida, em cada amostra, foi dividida pelo número de plântulas normais utilizadas, obtendo-se a biomassa fresca média de plântula (g plântula $\left.{ }^{-1}\right)$. Após a pesagem, as plântulas normais foram acondicionadas em sacos de papel e levadas para secar em estufa com circulação forçada de ar, regulada à temperatura de $60 \pm 2{ }^{\circ} \mathrm{C}$, por um período de $72 \mathrm{~h}$. Em seguida, foi realizada a pesagem do material, obtendo-se a biomassa seca com precisão de $0,01 \mathrm{~g}$. A massa total obtida, em cada amostra, foi dividida pelo número de plântulas normais utilizadas, obtendo-se a biomassa seca média de plântula (g plântula ${ }^{-1}$ ).

Os resultados foram submetidos à análise de variância, sendo as médias dos híbridos, quando significativas pelo teste $\mathrm{F}$, comparadas pelo teste de Tukey ao nível de $5 \%$ de probabilidade de erro $(P<0,05)$. Por se tratar de fator quantitativo, as médias dos níveis de potencial osmótico foram comparadas pela análise de regressão $(P<0,05)$. $O$ aplicativo computacional utilizado foi o SISVAR Sistema de análise de variância para dados balanceados. 
KAPPES, C. et al. Germinação, vigor de sementes e crescimento...

\section{RESULTADOS E DISCUSSÃO}

Os resultados da análise de variância revelaram efeitos significativos $(P<0,05)$ para os efeitos principais de híbridos e de níveis de potencial osmótico, bem como para a interação, para a maioria dos parâmetros avaliados (Tabela 3), demonstrando que os híbridos comportam-se de maneira distinta entre si em relação ao nível de potencial osmótico. Coerente ao encontrado no presente estudo, Moterle et al. (2006) avaliando germinação de sementes e crescimento de plântulas de três cultivares de milho-pipoca sob estresse hídrico e salino, verificaram interação significativa entre cultivares e níveis de potencial osmótico para germinação, primeira contagem de germinação, comprimento da raiz primária e parte aérea de plântula.

TABELA 3 - Primeira contagem de germinação (P.C.G.), contagem final de germinação (C.F.G.), velocidade de germinação (V.G.), comprimento da raiz primária (C.R.P.), comprimento da parte aérea (C.P.A.), relação parte aérea/raiz (A./R.), biomassa fresca de plântula (B.F.P.) e biomassa seca de plântula (B.S.P.) de híbridos de milho sob a influência de déficit hídrico induzido por soluções de manitol.

\begin{tabular}{|c|c|c|c|c|c|c|c|c|}
\hline \multirow{2}{*}{$\begin{array}{l}\text { Híbridos } \\
(\mathrm{H} .)\end{array}$} & \multicolumn{2}{|c|}{$-\%$} & $\begin{array}{l}\text { V.G. } \\
\text { (dias) }\end{array}$ & \multicolumn{2}{|c|}{$-\mathrm{cm}-$} & A./R. & \multicolumn{2}{|c|}{ — g plântula ${ }^{-1}$ — } \\
\hline & 66 & $83 a b$ & 4,83 & 10,49 & $4,15 \mathrm{~b}$ & $0,33 \mathrm{bc}$ & $0,90 a$ & $0,31 \mathrm{a}$ \\
\hline XB 6012 & 66 & $83 \mathrm{~b}$ & 4,81 & 10,46 & $4,24 \mathrm{~b}$ & $0,35 \mathrm{~b}$ & $0,83 \mathrm{~b}$ & $0,26 \mathrm{~b}$ \\
\hline XB 9003 & 68 & 89 a & 4,81 & 10,53 & $4,78 \mathrm{a}$ & $0,40 \mathrm{a}$ & $0,87 a b$ & $0,32 \mathrm{a}$ \\
\hline AG 9010 & 68 & $80 \mathrm{~b}$ & 4,66 & 10,72 & $4,12 b$ & $0,31 \mathrm{c}$ & $0,85 \mathrm{~b}$ & $0,27 \mathrm{~b}$ \\
\hline Valor $\mathrm{F}$ & $0,6^{N S}$ & $6,2^{*}$ & $2,25^{\mathrm{NS}}$ & $0,8^{N S}$ & $25,3^{*}$ & $26,7^{*}$ & $5,8^{*}$ & $44,5^{*}$ \\
\hline D.M.S. & 4,21 & 5,92 & 0,20 & 0,49 & 0,23 & 0,03 & 0,04 & 0,02 \\
\hline \multicolumn{9}{|l|}{$\begin{array}{c}\text { Níveis } \\
\Psi_{\text {os }}(\mathrm{N} .)\end{array}$} \\
\hline 0,0 & 97 & 97 & 4,01 & 17,25 & 10,75 & 0,62 & 1,38 & 0,26 \\
\hline$-0,3$ & 98 & 98 & 4,00 & 13,34 & 4,79 & 0,36 & 0,95 & 0,29 \\
\hline$-0,6$ & 88 & 96 & 4,25 & 9,48 & 3,81 & 0,41 & 0,79 & 0,30 \\
\hline$-0,9$ & 39 & 77 & 5,25 & 7,77 & 1,33 & 0,17 & 0,64 & 0,30 \\
\hline$-1,2$ & 14 & 50 & 6,12 & 4,91 & 0,93 & 0,19 & 0,56 & 0,31 \\
\hline Valor F & $933,1^{*}$ & $135,5^{*}$ & $260,5^{*}$ & $1086,8^{*}$ & $3254,5^{\star}$ & $482,8^{*}$ & $558,1^{*}$ & $17,6^{*}$ \\
\hline \multicolumn{9}{|l|}{$\begin{array}{c}\text { Interação } \\
\text { (H. x N.) }\end{array}$} \\
\hline Valor $\mathrm{F}$ & $12,3^{*}$ & $8,2^{*}$ & $3,4^{*}$ & $3,3^{*}$ & $23,7^{*}$ & $17,3^{*}$ & $2,7^{*}$ & $1,1^{\mathrm{NS}}$ \\
\hline C.V. (\%) & 7,48 & 8,44 & 5,07 & 5,56 & 6,40 & 9,54 & 6,33 & 6,80 \\
\hline
\end{tabular}

As médias da porcentagem de plântulas normais nos testes de germinação e de vigor de sementes, bem como do crescimento de plântulas encontram-se na Tabela 4 , em que se tem o comportamento de cada híbrido dentro dos respectivos níveis de potencial osmótico através do desdobramento da interação $(P<0,05)$. De maneira geral, grande variabilidade entre os híbridos foi constatada, a qual pode ser justificada pelo fato da resposta das sementes, colocadas para germinar sob déficit hídrico, terem se mostrado dependente da espécie ou da cultivar, conforme citado por Martinelli-Seneme et al. (2000).

Para o vigor de sementes, na primeira contagem de germinação (Tabela 4), não houve diferença entre os híbridos nos níveis zero e -0,3 $\mathrm{MPa}$ de potencial osmótico $(P<0,05)$, sendo que as sementes apresentaram bom poder germinativo nestas condições (acima de 95\%). Contudo, Moterle et al. (2006), verificaram diferenças no percentual de plântulas normais durante a primeira contagem de germinação entre cultivares de milho-pipoca quando as sementes foram submetidas ao nível de $-0,3 \mathrm{MPa}$ de potencial osmótico. No nível de $-0,6$ $\mathrm{MPa}$ de potencial osmótico, as sementes dos híbridos XB 6010 e XB 9003 apresentaram menor vigor em comparação aos demais híbridos, enquanto no nível de $-0,9 \mathrm{MPa}$, as sementes dos híbridos XB 6012 e AG 9010 foram as menos vigorosas em relação aos demais, demonstrando 
KAPPES, C. et al. Germinação, vigor de sementes e crescimento...

TABELA 4 - Desdobramento da interação significativa entre híbridos de milho e níveis de potencial osmótico para primeira contagem, contagem final e velocidade de germinação, comprimento da raiz primária e da parte aérea e biomassa fresca de plântula sob a influência de déficit hídrico induzido por soluções de manitol. UNESP, Ilha Solteira, São Paulo, Brasil (2009).

\begin{tabular}{|c|c|c|c|c|c|}
\hline \multirow{2}{*}{ Híbridos } & \multicolumn{5}{|c|}{ Níveis de potencial osmótico (MPa) } \\
\hline & 0,0 & $-0,3$ & $-0,6$ & $-0,9$ & $-1,2$ \\
\hline & \multicolumn{5}{|c|}{ Primeira contagem de germinação (\%) } \\
\hline XB 6010 & 97 a & 98 a & $84 \mathrm{~b}$ & $48 \mathrm{a}$ & $5 c$ \\
\hline XB 6012 & 96 a & 98 a & $94 \mathrm{a}$ & $33 \mathrm{~b}$ & $10 \mathrm{bc}$ \\
\hline XB 9003 & $95 \mathrm{a}$ & 96 a & $78 \mathrm{~b}$ & $50 \mathrm{a}$ & $18 a b$ \\
\hline \multirow[t]{2}{*}{ AG 9010} & 99 a & 98 a & 96 a & $23 c$ & $23 a$ \\
\hline & \multicolumn{5}{|c|}{ Contagem final de germinação (\%) } \\
\hline XB 6010 & $97 \mathrm{a}$ & $98 \mathrm{a}$ & $96 \mathrm{a}$ & $88 \mathrm{a}$ & $36 \mathrm{c}$ \\
\hline XB 6012 & 97 a & $98 \mathrm{a}$ & 95 a & $73 b$ & $51 \mathrm{~b}$ \\
\hline XB 9003 & 95 a & 96 a & 95 a & 93 a & $65 a$ \\
\hline \multirow[t]{2}{*}{ AG 9010} & 99 a & 98 a & 99 a & $52 \mathrm{c}$ & $50 \mathrm{~b}$ \\
\hline & \multicolumn{5}{|c|}{ Velocidade de germinação (dias) } \\
\hline XB 6010 & $4,02 \mathrm{a}$ & $4,0 \mathrm{a}$ & $4,35 a b$ & $5,40 a$ & $6,40 \mathrm{~b}$ \\
\hline XB 6012 & $4,02 \mathrm{a}$ & $4,0 \mathrm{a}$ & $4,05 \mathrm{a}$ & 5,65 a & $6,35 \mathrm{~b}$ \\
\hline XB 9003 & $4,00 \mathrm{a}$ & $4,0 \mathrm{a}$ & $4,52 \mathrm{~b}$ & 5,37 a & $6,17 \mathrm{~b}$ \\
\hline \multirow[t]{2}{*}{ AG 9010} & $4,00 \mathrm{a}$ & $4,0 \mathrm{a}$ & $4,07 a b$ & $5,67 \mathrm{a}$ & $5,55 \mathrm{a}$ \\
\hline & \multicolumn{5}{|c|}{ Comprimento da raiz primária $(\mathrm{cm})$} \\
\hline XB 6010 & $17,16 \mathrm{a}$ & $13,02 \mathrm{a}$ & $9,24 \mathrm{a}$ & $8,45 a$ & $4,63 \mathrm{~b}$ \\
\hline XB 6012 & 17,67 a & 13,69 a & $9,21 \mathrm{a}$ & $6,85 b$ & $4,85 a b$ \\
\hline XB 9003 & $17,24 \mathrm{a}$ & 13,33 a & 9,43 a & $8,24 \mathrm{a}$ & $4,40 \mathrm{~b}$ \\
\hline \multirow[t]{2}{*}{ AG 9010} & $16,93 \mathrm{a}$ & $13,33 \mathrm{a}$ & $10,02 \mathrm{a}$ & $7,55 a b$ & 5,76 a \\
\hline & \multicolumn{5}{|c|}{ Comprimento da parte aérea $(\mathrm{cm})$} \\
\hline XB 6010 & $10,74 \mathrm{~b}$ & $4,81 \mathrm{a}$ & $2,67 b$ & $1,65 \mathrm{a}$ & $0,85 \mathrm{a}$ \\
\hline XB 6012 & $9,75 \mathrm{c}$ & $4,61 \mathrm{a}$ & $4,95 \mathrm{a}$ & $0,96 \mathrm{~b}$ & $0,94 \mathrm{a}$ \\
\hline XB 9003 & $11,35 \mathrm{a}$ & $4,75 a$ & 4,79 a & $1,84 \mathrm{a}$ & $1,18 \mathrm{a}$ \\
\hline \multirow[t]{2}{*}{ AG 9010} & $11,14 a b$ & 4,98 a & $2,84 \mathrm{~b}$ & $0,88 \mathrm{~b}$ & $0,75 \mathrm{a}$ \\
\hline & \multicolumn{5}{|c|}{ Relação parte aérea/raiz } \\
\hline XB 6010 & $0,62 \mathrm{a}$ & $0,37 \mathrm{a}$ & $0,29 \mathrm{~b}$ & $0,19 a b$ & $0,19 \mathrm{~b}$ \\
\hline XB 6012 & $0,55 \mathrm{~b}$ & 0,33 a & $0,54 \mathrm{a}$ & $0,14 \mathrm{bc}$ & $0,19 \mathrm{~b}$ \\
\hline XB 9003 & $0,66 \mathrm{a}$ & 0,35 a & $0,51 \mathrm{a}$ & $0,22 \mathrm{a}$ & 0,27 a \\
\hline \multirow[t]{2}{*}{ AG 9010} & $0,66 a$ & $0,37 \mathrm{a}$ & $0,29 b$ & $0,12 \mathrm{c}$ & $0,13 b$ \\
\hline & \multicolumn{5}{|c|}{ Biomassa fresca de plântula (g plântula ${ }^{-1}$ ) } \\
\hline XB 6010 & $1,46 \mathrm{a}$ & $0,94 \mathrm{a}$ & $0,81 \mathrm{a}$ & $0,69 \mathrm{a}$ & $0,61 \mathrm{a}$ \\
\hline XB 6012 & $1,32 \mathrm{~b}$ & 0,99 a & $0,74 \mathrm{a}$ & $0,58 \mathrm{~b}$ & $0,53 \mathrm{a}$ \\
\hline XB 9003 & $1,34 \mathrm{~b}$ & $0,94 \mathrm{a}$ & $0,79 a$ & $0,70 \mathrm{a}$ & 0,58 a \\
\hline \multirow[t]{2}{*}{ AG 9010} & $1,39 a b$ & $0,91 \mathrm{a}$ & $0,82 a$ & $0,50 \mathrm{~b}$ & $0,53 \mathrm{a}$ \\
\hline & \multicolumn{5}{|c|}{ Biomassa seca de plântula (g plântula ${ }^{-1}$ ) } \\
\hline XB 6010 & $0,28 \mathrm{a}$ & $0,30 a b$ & $0,32 \mathrm{a}$ & $0,32 \mathrm{a}$ & $0,34 \mathrm{a}$ \\
\hline XB 6012 & $0,22 \mathrm{~b}$ & $0,28 a b$ & $0,27 \mathrm{~b}$ & $0,27 \mathrm{~b}$ & $0,27 \mathrm{~b}$ \\
\hline XB 9003 & $0,28 \mathrm{a}$ & $0,31 \mathrm{a}$ & $0,34 \mathrm{a}$ & $0,33 a$ & $0,33 \mathrm{a}$ \\
\hline AG 9010 & $0,24 \mathrm{~b}$ & $0,27 \mathrm{~b}$ & $0,26 \mathrm{~b}$ & $0,28 \mathrm{~b}$ & $0,28 \mathrm{~b}$ \\
\hline
\end{tabular}

Médias seguidas por letras distintas minúsculas nas colunas de cada parâmetro diferem entre si pelo teste de Tukey ao nível de $5 \%$ de probabilidade $(P<0,05)$. 
KAPPES, C. et al. Germinação, vigor de sementes e crescimento...

um indicativo de relação com a massa de cem sementes (Tabela 1), uma vez que sementes com maior massa apresentavam maiores reservas nutricionais, que resultavam em maior vigor durante o período inicial de desenvolvimento da plântula. No nível mais negativo $(-1,2 \mathrm{MPa}$ de potencial osmótico), o decréscimo na absorção de água pelas sementes ocasionou redução drástica no percentual de plântulas normais, sendo que as sementes do XB 6010 apresentaram menor potencial de germinação, apesar de não ter se diferenciado estatisticamente do XB 6012 em tal condição de déficit hídrico.
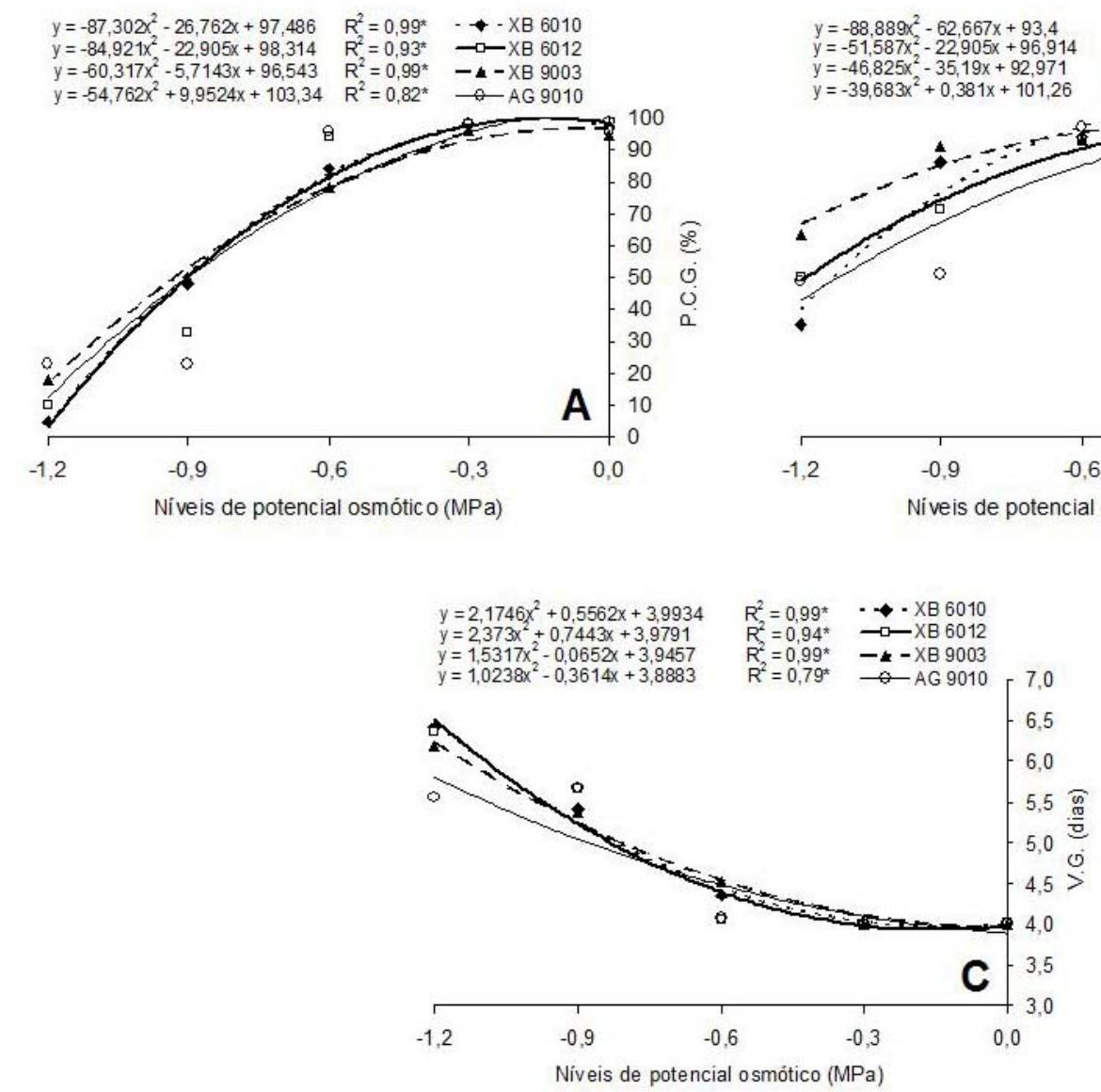

FIGURA 1 - Primeira contagem de germinação - P.C.G. (A), contagem final de germinação - C.F.G. (B) e Velocidade de germinação - V.G. (C) das sementes de híbridos de milho sob a influência de déficit hídrico induzido por soluções de manitol. UNESP, Ilha Solteira, São Paulo, Brasil (2009). ${ }^{(*)}$ Significativo pelo teste $\mathrm{F}$ ao nível de $5 \%$ de probabilidade $(P<0,05)$.

A contagem final de germinação (Tabela 4) não apresentou diferença entre os híbridos quando as sementes foram submetidas aos níveis zero, $-0,3$ e $-0,6 \mathrm{MPa}$ de potencial osmótico $(P<0,05)$, sendo que estas apresentaram germinação satisfatória em tais condições, demonstrando boa viabilidade. A alta porcentagem de germinação mantida em tais condições de déficit hídrico demonstra claramente a semelhança no vigor e na viabilidade entre as sementes dos híbridos avaliados. Braccini et al. (1996) avaliando a germinação e vigor de sementes de soja sob déficit hídrico induzido por soluções de
$\mathrm{Na}$ análise de regressão (Figura $1 \mathrm{~A}$ ), o modelo quadrático foi o que melhor se ajustou aos dados de primeira contagem de germinação em função dos níveis de potencial osmótico. Observouse decréscimo no vigor das sementes de todos os híbridos à medida que o potencial osmótico da solução foi diminuído. Bruni \& Leopold (1992) sugerem que essa redução é causada pelo déficit de água, o que provoca a perda progressiva da turgescência protoplasmática e um aumento na concentração de solutos. Desses efeitos resulta, inicialmente, um distúrbio na função celular e, por fim, danos no sistema de biomembranas.

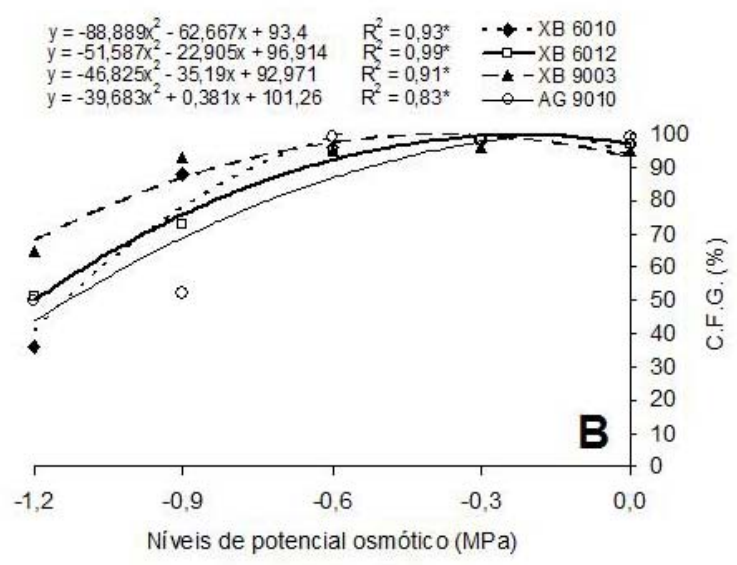

cloreto de sódio $(\mathrm{NaCl})$, manitol e polietileno glicol (PEG 6000), também verificaram valores de germinação bastante satisfatórios quando submetidas a potencial osmótico de até $-0,3 \mathrm{MPa}$ de manitol e $\mathrm{NaCl}$. Porém, a partir deste nível, em $0,6 \mathrm{MPa}$ de potencial osmótico, diferentemente do que ocorreu neste ensaio, houve redução significativa na germinação das sementes, sendo esse decréscimo mais acentuado para $\circ \mathrm{NaCl}$ do que para o manitol. Constataram ainda que, mesmo em potencial osmótico de $-0,9 \mathrm{MPa}$, o manitol não causou uma redução tão acentuada na germinação 
KAPPES, C. et al. Germinação, vigor de sementes e crescimento...

das sementes, apresentando valor superior a $65 \%$ neste nível, sendo justificado pela maior capacidade estressante do PEG 6000, em relação aos outros dois agentes osmóticos.

Os híbridos apresentaram comportamento diferente na germinação final somente quando as sementes foram acondicionadas em solução osmótica de $-0,9$ e $-1,2 \mathrm{MPa}(P<0,05)$. Isto indica que a germinação de sementes de milho em condições de campo, nestes respectivos potenciais osmóticos, torna-se dependente do material genético (híbrido no caso), ou seja, o fator genótipo será determinante quanto à tolerância ou não ao déficit hídrico presente no solo. Logicamente, outros fatores também podem atuar de forma conjunta ao déficit hídrico, potencializando os danos ao processo germinativo das sementes, como a temperatura do solo e do ar. Sementes do híbrido XB 6010, juntamente com as do XB 9003, apresentaram maior percentual germinativo em $-0,9$ $\mathrm{MPa}$ de potencial osmótico, com 88 e 93\%, respectivamente. Embora tenha ocorrido redução na porcentagem de plântulas normais de todos os híbridos avaliados em -0,9 e -1,2 MPa, somente as sementes do híbrido XB 9003 apresentaram maior capacidade germinativa $(65 \%)$ em nível de $-1,2$ $\mathrm{MPa}$ de potencial osmótico, indicando menor redução na viabilidade das sementes e maior capacidade de superar condições restritas de disponibilidade de água. De acordo com Ávila et al. (2007), o estresse hídrico contribui para a diminuição da percentagem de germinação das sementes, sendo que para cada espécie existe um valor de potencial hídrico no solo, abaixo do qual a germinação não ocorre.

Todos os híbridos apresentaram comportamento similar para a contagem final de germinação, sendo possível o ajuste de equações de regressão quadrática para cada um deles (Figura 1B). A redução na germinação final das sementes dos híbridos com a diminuição do potencial osmótico está coerente com a verificação realizada por Smith et al. (1989), cuja germinação de sementes de sorgo e milheto decresceram uniformemente com a diminuição do potencial osmótico, porém, em -1,2 MPa de potencial osmótico não ocorreu a germinação, diferente do encontrado neste ensaio. A redução na germinação de sementes dos híbridos de milho verificada no presente estudo em maiores concentrações de manitol, especialmente em -1,2 MPa de potencial osmótico, pode ser atribuída à redução da velocidade e quantidade de água absorvida pelas sementes.

Para velocidade de germinação (Tabela 4), os híbridos não apresentaram diferença em suas médias quando as sementes foram submetidas aos níveis zero, $-0,3$ e $-0,9 \mathrm{MPa}$ de potencial osmótico $(P<0,05)$. No nível de $-0,6 \mathrm{MPa}$ de potencial osmótico, o híbrido XB 9003 foi o que apresentou menor velocidade de germinação, apesar de não ter se diferenciado significativamente dos híbridos XB 6010 e AG 9010, portanto, maior número de dias para a germinação das sementes. Sob condição de déficit hídrico em -1,2 MPa de potencial osmótico, o híbrido AG 9010 apresentou maior velocidade de germinação, portanto, menor número de dias para a germinação e consequentemente, maior vigor das sementes em relação aos demais híbridos. Isso demonstra que a velocidade de germinação das sementes é dependente dos híbridos nos potenciais $-0,6$ e -1,2 MPa de potencial osmótico.

O modelo quadrático foi o que melhor se ajustou aos resultados de velocidade de germinação durante a análise de regressão (Figura 1C). Não houve redução drástica na velocidade de germinação nos níveis zero, - -0,3 e - -0,6 MPa de potencial osmótico, diferentemente dos resultados constatados por Braccini et al. (1996), ao concluírem que potenciais inferiores a $-0,3 \mathrm{MPa}$ já foram suficientes para provocarem redução acentuada na velocidade de germinação de plântulas de soja. De maneira geral, pode-se observar em todos os híbridos, uma acentuada redução na velocidade de germinação nos níveis de $-0,9$ e -1,2 MPa de potencial osmótico (maior número de dias para a germinação das sementes), confirmando um dos efeitos do déficit hídrico, que é o de retardar o início da germinação das sementes, conforme descrito por Ávila et al. (2007). Portanto, tais condições de disponibilidade hídrica fazem com que as sementes necessitem maior número de dias para germinarem, o que em condições de campo não é desejável, pois o atraso na germinação predispõe as sementes a uma maior exposição à ação dos patógenos e ataque de insetos praga. Assim, a relação entre o potencial hídrico do meio e o tempo de germinação é uma variável importante, sobretudo nas regiões onde a superfície do solo é seca.

Quanto ao comprimento da raiz primária de plântula (Tabela 4), os resultados foram condizentes com aqueles observados na porcentagem final de germinação, em que os híbridos não apresentaram diferença em suas médias nos níveis zero, $-0,3$ e $-0,6 \mathrm{MPa}$ de potencial osmótico $(P<0,05)$, discordando com os resultados de Moterle et al. (2006), ao obterem diferenças entre cultivares de milho-pipoca nestes mesmos níveis de potencial. No presente ensaio, no nível de $-0,9 \mathrm{MPa}$ de potencial osmótico, plântulas dos híbridos XB 6010 e XB 9003 obtiveram maior comprimento da raiz primária, apesar de não terem sido superior estatisticamente do híbrido AG 9010 , que por sua vez, obteve o melhor resultado quando submetido ao nível de $-1,2 \mathrm{MPa}$ de potencial osmótico, não diferindo do híbrido XB 6012 neste nível.

$\mathrm{Na}$ análise de regressão (Figura 2A), o modelo quadrático novamente foi o que melhor se ajustou aos dados de comprimento da raiz primária de plântula. Na representação gráfica, observa-se claramente que, à medida que diminui o potencial osmótico da solução no substrato, o comprimento da raiz primária decresce em todos os híbridos avaliados, apresentando certa coerência com os resultados obtidos por Santos et al. (1992), que ao avaliarem o efeito salino e hídrico na germinação e 
KAPPES, C. et al. Germinação, vigor de sementes e crescimento...

vigor de sementes de soja, observaram redução no crescimento das raízes quando as sementes foram submetidas a condições de estresse. Além do estresse hídrico afetar a embebição, a velocidade e a germinação, um dos outros efeitos é a redução do crescimento, causada pela diminuição da expansão celular. O processo de alongamento celular e a síntese de parede são muito sensíveis ao déficit hídrico, e a redução do crescimento, como conseqüência da diminuição do alongamento celular, seria causada por um decréscimo na turgescência dessas células (Bewley \& Black, 1994).
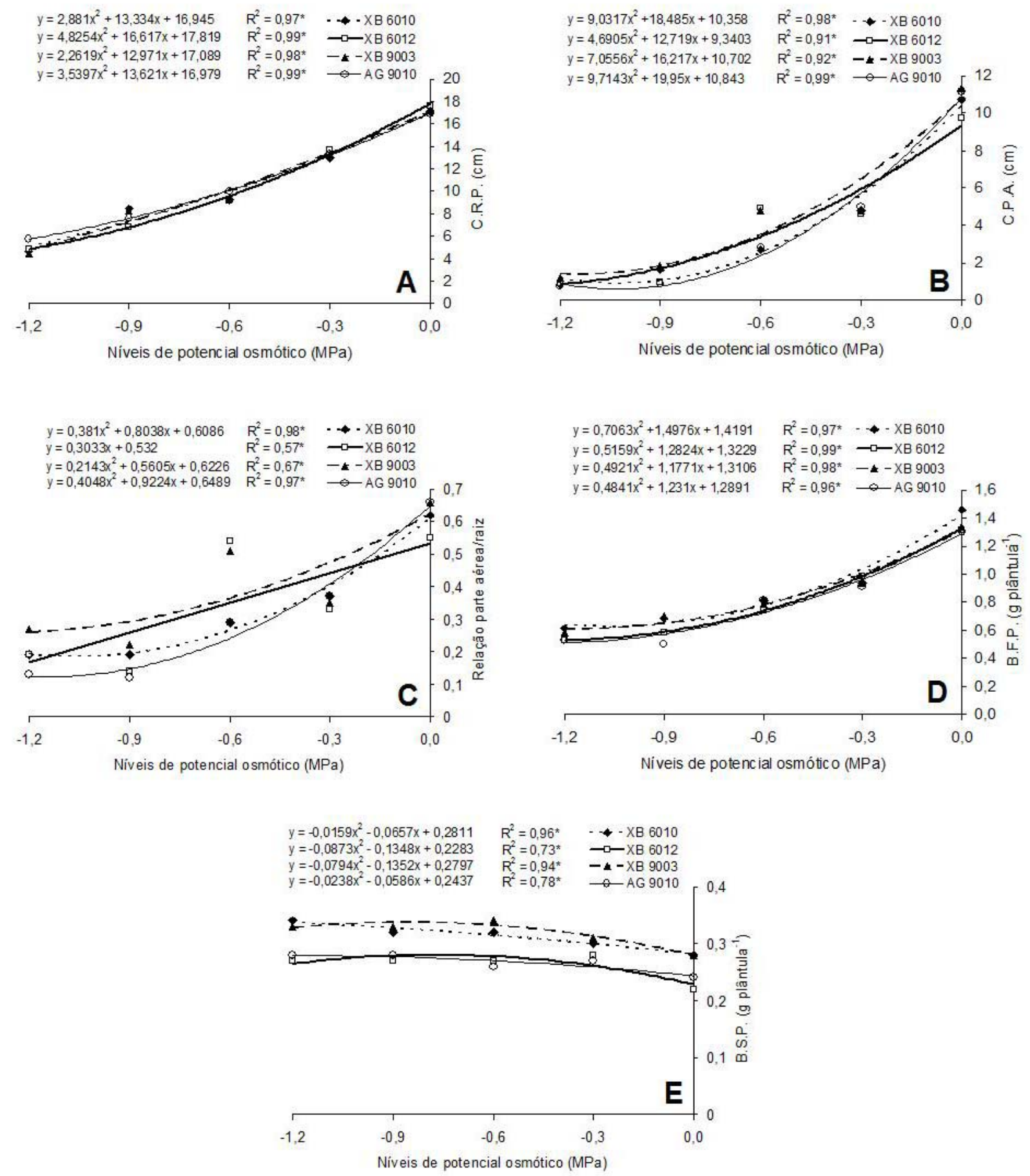

FIGURA 2 - Comprimento da raiz primária - C.R.P. (A), comprimento da parte aérea - C.P.A. (B), relação parte aérea/raiz (C), biomassa fresca de plântula - B.F.P. (D) e biomassa seca de plântula - B.S.P. (E) de híbridos de milho sob a influência de déficit hídrico induzido por soluções de manitol. UNESP, Ilha Solteira, São Paulo, Brasil (2009). ${ }^{(*)}$ Significativo pelo teste $\mathrm{F}$ ao nível de $5 \%$ de probabilidade $(P<0,05)$. 
KAPPES, C. et al. Germinação, vigor de sementes e crescimento...

No que diz respeito ao comprimento da parte aérea de plântula (Tabela 4), houve comportamento distinto entre os híbridos no nível zero e -0,6 e -0,9 MPa de potencial osmótico, sendo que os resultados do híbrido XB 9003, apesar de não terem se diferenciado estatisticamente dos resultados do híbrido AG $9010(P<0,05)$, resultaram em plântulas com maior comprimento da parte aérea quando submetida a embebição com água desmineralizada (nível zero). Em solução de -0,6 $\mathrm{MPa}$ de potencial osmótico, os melhores resultados foram conseguidos com os híbridos XB 6012 e XB 9003 , sendo que este último, também foi superior estatisticamente sob condição de déficit hídrico em $0,9 \mathrm{MPa}$ de potencial osmótico, entretanto, não diferiu do híbrido XB 6010 neste mesmo nível.

Coerente ao ocorrido nos resultados dos demais testes, houve redução no comprimento da parte aérea de plântula à medida que o potencial osmótico da solução foi diminuído, tornando possível o ajuste de equações de regressão quadrática para os híbridos dentro dos níveis de potencial osmótico (Figura 2B). Assim, pode-se inferir que a restrição hídrica influenciou a velocidade dos processos fisiológicos e bioquímicos, restringindo o desenvolvimento da plântula, pois segundo Dell'Aquila (1992), a redução no comprimento de plântula se deve às mudanças na turgescência celular, em função da diminuição da síntese de proteína nas condições de estresse hídrico. Taiz \& Zeiger (2004) relataram que o primeiro efeito mensurável do estresse hídrico é a diminuição no crescimento, causada pela redução da expansão celular. Moraes \& Menezes (2003), avaliando o desempenho de sementes de soja sob condições diferentes de potencial osmótico, concluíram que os menores potenciais reduziram o comprimento das plântulas.

Para a relação parte aérea/raiz de plântula, os híbridos apresentaram comportamento distinto entre as médias em todos os níveis $(P<0,05)$, exceto em -0,3 MPa de potencial osmótico. No nível zero, os híbridos XB 6010, XB 9003 e AG 9010 foram os que apresentaram maior relação parte aérea/raiz, os quais não diferiram entre si. Em -0,6 MPa de potencial osmótico, os híbridos XB 6012 e XB 9003 apresentaram maior relação parte aérea/ raiz. Já em -0,9 MPa de potencial osmótico, o XB 9003 foi o que obteve a maior relação parte aérea/ raiz, apesar de não ter se diferido do XB 6010 neste nível, enquanto em -1,2 MPa de potencial osmótico, apenas o XB 9003 foi superior aos demais híbridos para este parâmetro mensurado. $\mathrm{Na}$ análise de regressão (Figura 2C), os híbridos XB 6010, XB 9003 e AG 9010 tiveram seus dados ajustados modelo quadrático, enquanto os dados do híbrido XB 6012 ajustaram-se melhor com o modelo linear decrescente. Nota-se, que a relação parte aérea/ raiz de plântula diminui à medida que os potenciais tornam-se mais negativos, ratificando com Castro \& Kluge (1999), ao relatarem que fatores como alta luminosidade e déficit hídrico podem reduzir esta relação. Os referidos autores ainda relatam que o crescimento do sistema radicular está intimamente relacionado com o da parte aérea e que a relação parte aérea/raiz é um importante parâmetro na determinação do potencial produtivo da planta de milho.

No tocante à biomassa fresca de plântula (Tabela 4), houve diferença entre os híbridos somente quando as sementes foram embebidas com água desmineralizada e $-0,9 \mathrm{MPa}$ de potencial osmótico $(P<0,05)$. As sementes do híbrido XB 6010 originaram plântulas com maior biomassa fresca, contudo, não houve diferença significativa em comparação aos híbridos AG 9010 e XB 9003 no nível zero e -0,9 MPa de potencial osmótico, respectivamente. Dentro dos níveis de potencial osmótico, a biomassa fresca de plântula de cada híbrido teve melhor ajuste de seus resultados com o modelo quadrático na análise de regressão (Figura 2D). Verifica-se claramente na representação gráfica, a dificuldade imposta pelos níveis negativos de potencial osmótico $(-0,3,-0,6,-0,9$ e -1,2 MPa) em relação ao acúmulo de biomassa durante 0 desenvolvimento inicial das plântulas de milho. A redução da biomassa fresca de plântula em função da restrição hídrica, quando comparada com a testemunha, pode ser atribuída à menor velocidade dos processos fisiológicos e bioquímicos ou pela dificuldade de hidrólise e mobilização das reservas da semente, conforme ressaltado por Bewley \& Black (1994). O decréscimo da absorção de água pelas sementes evidencia novamente o efeito prejudicial do déficit hídrico sobre a germinação e vigor das sementes e sobre o crescimento das plântulas de milho.

Apesar de não haver interação significativa $(P<0,05)$ entre híbridos e níveis de potencial osmótico para a biomassa seca de plântula (Tabela 3 ), houve comportamento distinto entre os híbridos dentro dos respectivos níveis no desdobramento (Tabela 4). Os híbridos XB 6010 e XB 9003 tiveram comportamento similar nos níveis zero, -0,6, -0,9 e $1,2 \mathrm{MPa}$ de potencial osmótico ao apresentarem maior biomassa seca de plântula, diferenciando significativamente dos demais $(P<0,05)$ nestes níveis. Em -0,3 $\mathrm{MPa}$ de potencial osmótico, o híbrido XB 9003 foi o que apresentou maior biomassa seca de plântula, contudo, não diferençou-se significativamente dos híbridos $\mathrm{XB}$ 6010 e XB 6012.Na análise de regressão (Figura $2 \mathrm{E}$ ), o modelo quadrático foi o que melhor se ajustou aos dados de matéria seca de plântula. $\mathrm{Na}$ representação gráfica, diferente ao verificado para biomassa fresca de plântula, a biomassa seca apresentou acréscimo à medida que o potencial osmótico da solução foi diminuído. Porém, o acréscimo foi pouco acentuado e, além disse, houve uma tendência quadrática na resposta dos dados. Costa et al. (2004), ao estudarem o estresse hídrico induzido por manitol em sementes de soja, verificaram redução linear para massa seca aérea de plântula à medida que os potenciais hídricos tornaram-se mais negativos.

Conforme pôde ser observado neste estudo, existem níveis de potencial osmótico que provocam redução no desempenho das sementes, 
KAPPES, C. et al. Germinação, vigor de sementes e crescimento...

tornando-se críticos tanto para a germinação e o vigor das sementes quanto para o desenvolvimento das plântulas. Os resultados revelam a importância da avaliação dos potenciais hídricos do substrato, considerados críticos para a germinação das sementes e crescimento das plântulas de milho, além da necessidade de seleção criteriosa de híbridos que possam apresentar tolerância às condições de déficit hídrico no meio.

\section{CONCLUSÕES}

Os resultados encontrados permitem as seguintes constatações: i) O déficit hídrico, simulado com soluções de manitol, provoca redução no desempenho de sementes de híbridos de milho; ii) Há comportamento diferenciado dos híbridos quanto à tolerância à condição de déficit hídrico; iii) Há redução da germinação, do vigor de sementes e do crescimento de plântulas de milho à medida que o potencial osmótico da água torna-se mais negativo.

\section{AGRADECIMENTOS}

Ao Departamento de Biologia e Zootecnia da Universidade Estadual Paulista "Júlio de Mesquita Filho" (UNESP) pela concessão do laboratório e de materiais e à Fazenda de Ensino, Pesquisa e Extensão (FEPE) da UNESP pela disponibilização das sementes.

\section{CONFLITOS DE INTERESSES}

Os autores declaram que não há relação dos mesmos com as empresas produtoras dos híbridos testados neste trabalho, em termos de consultoria, financiamento ou bolsas.

\section{REFERÊNCIAS}

1. ALMANSOURI, M.; KINET, J. M.; LUTTS, S. Effect of salt and osmotic stresses on germination in durum wheat (Triticum durum Desf.). Plant and Soil, v. 231, n. 2, p. 243-254. 2001.

2. ÁVILA, M. R. et al. Influência do estresse hídrico simulado com manitol na germinação de sementes e crescimento de plântulas de canola. Revista Brasileira de Sementes, v. 29, n. 1, p. 98-106, 2007.

3. BEWLEY, J. D.; BLACK, M. Seeds: physiology of development and germination. 2. ed. New York: Plenum Press, 1994. $445 \mathrm{p}$.

4. BOTELHO, B. A.; PEREZ, S. C. J. G. A. Estresse hídrico e reguladores de crescimento na germinação de sementes de canafístula. Scientia Agricola, v. 58, n. 1, p. 43-49, 2001.

5. BRACCINI, A. L. et al. Germinação e vigor de sementes de soja sob estresse hídrico induzido por soluções de cloreto de sódio, manitol e polietileno glicol. Revista Brasileira de Sementes, v. 18, n. 1, p. 10-16, 1996.

6. BRAGA, L. F. et al. Efeito da disponibilidade hídrica do substrato na qualidade fisiológica de sementes de feijão. Revista Brasileira de Sementes, v. 21, n. 2, p. 95-102, 1999.

7. BRASIL. Ministério da Agricultura e da Reforma Agrária. Regras para análise de sementes. Brasília: SNDA/DNDV/ CLAV, 1992. $365 \mathrm{p}$

8. BRUNI, F. B.; LEOPOLD, A. C. Cytoplasmic glass formation in maize embryos. Seed Science Research, v. 2, n. 4, p. 251-253, 1992

9. CARVALHO, N. M.; NAKAGAWA, J. Sementes: ciência, tecnologia e produção. 4. ed. Jaboticabal: Funep, 2000. 588 p.

10. CASTRO, P. R. C.; KLUGE, R. A. Ecofisiologia de cultivos anuais: trigo, milho, soja, arroz e mandioca. São Paulo: Nobel, 1999. $126 \mathrm{p}$.

11. COSTA, P. R. et al. Estresse hídrico induzido por manitol em sementes de soja de diferentes tamanhos. Revista Brasileira de Sementes, v. 26, n. 2, p. 105-113, 2004.

12. DELL'AQUILA, A. Water uptake and protein synthesis in germinating wheat embryos under the osmotic stress of polyethylene glycol. Annals of Botany, v. 69, n. 2, p. 167-171, 1992.

13. EDMOND, J. B.; DRAPALA, W. J. The effects of temperature, sand, soil, and acetone on germination of okra seeds. Proceedings of the American Society for Horticultural Science, v. 71, n. 5, p. 428-434, 1958.

14. KHAJEH-HOSSEINI, M.; POWELL, A. A.; BINGHAM, I. J. The interaction between salinity stress and seed vigour during germination of soybean seeds. Seed Science and Technology, v. 31, n. 3, p. 715-725, 2003.

15. MACHADO, J. C. et al. Uso da restrição hídrica na inoculação de fungos em sementes de milho. Revista Brasileira de Sementes, v. 23, n. 2, p. 88-94, 2001.

16. MARTINELLI-SENEME, A.; MARTINS, C. C.; NAKAGAWA, J. Germinação de milho cv. AL-34 em função do tamanho da semente e do potencial hídrico do substrato. Revista Brasileira de Sementes, v. 22, n. 2, p. 131-138, 2000.

17. MORAES, G. A. F.; MENEZES, N. L. Desempenho de sementes de soja sob condições diferentes de potencial osmótico. Ciência Rural, v. 33, n. 2, p. 219-226, 2003.

18. MOTERLE, L. M. et al. Germinação de sementes e crescimento de plântulas de cultivares de milho-pipoca submetidas ao estresse hídrico e salino. Revista Brasileira de Sementes, v. 28, n. 3, p. 169-176, 2006.

19. SALISBURY, F. B.; ROSS, C. W. Plant physiology. 4. ed. California: Wadsworth Publishing, 1992. 682 p.

20. SANTOS, V. L. M. et al. Efeito do estresse salino e hídrico na germinação e vigor de sementes de soja. Revista Brasileira de Sementes, v. 14, n. 2, p. 189-194, 1992.

21. SILVA, L. M. M. et al. Estresse hídrico e condicionamento osmótico na qualidade fisiológica de sementes de Cnidoscolus juercifolius. Revista Brasileira de Engenharia Agrícola e Ambiental, v. 9, n. 1, p.66-72, 2005.

22. SMITH, R. L.; HOVELAND, C. S.; HANA, W. W. Water stress and temperature in relation to seed germination of pearl millet and sorghum. Agronomy Journal, v. 81, n. 2, p. 303-305, 1989.

23. TAIZ, L.; ZEIGER, E. Fisiologia vegetal. 3. ed. Porto Alegre: ARTMED, 2004, 719 p.

24. TONIN, G. A. et al. Influência do genótipo e do vigor no desempenho germinativo de sementes de milho em condições de estresse hídrico. Revista Brasileira de Sementes, v. 22, n. 1, p. 276-279, 2000. 